\title{
Antipassivization and Pivot Construction in Ergative Languages
}

\author{
WANG Ran \\ University at Buffalo, SUNY, Buffalo, USA
}

\begin{abstract}
Topics on antipassivization and pivot construction in ergative languages have drawn many discussions among linguists. Different approaches and accounts have been proposed. However, ergative-absolutive case assignment and phenomena like split ergativity are still harsh questions for linguists to offer a natural and proper explanation. This present paper, based on the discussion on Manning's Inverse Grammatical Relation account (Manning, 1995), proposes a modified approach on case assignment and antipassivization rule for the pivot construction of certain ergative languages within HPSG framework. This would bring more lights to the understanding of ergativity in the future.
\end{abstract}

Keywords: ergativity, antipassivization, pivot construction

\section{Introduction}

\section{Brief Introduction to Ergativity and Ergative Languages}

Most languages in the world, if not all, have both transitive and intransitive verbs, with transitive verbs taking two core arguments ${ }^{1}$ and intransitive verbs taking only one core argument. In this paper, the only core argument of an intransitive verb is referred as subject of the verb (hereafter $\mathrm{S}$ ), and the two core arguments of a transitive verb are labeled as agent (hereafter A) and patient (hereafter P) respectively. Please note that agent (A) in this paper does not only refer to the agent of the semantic roles; it includes all agent-like arguments such as the doner in giving, the experiencer in seeing and so on. Dixon $(1994$, p. 8$)$ defines agent as "that role which is most likely to be relevant to the success of the activity". Similarly, P stands for all patient-like arguments which may include receiver of giving and the experienced in seeing; it refers to all arguments that is affected by the verb.

As far as case marking is concerned, linguists found out that there are two main ways world languages map S, A, and $\mathrm{P}$ argument into their clause structures. One of aligns $\mathrm{S}$ with $\mathrm{A}$ together and marks them with one case, leaving $\mathrm{P}$ separately with another case. These languages are called nominative-accusative languages which include Indo-European languages such as Latin and English. The other way of alignment is to treat $\mathrm{S}$ and $\mathrm{P}$ together and mark A differently. Dyirbal, West Greenlandic are examples of these languages. They are called ergative-absolutive languages. This alignment difference may take place in different ways. The difference could be marked by case marker on respective NPs, or it could be marked by verb conjugation. Due to the limitation of the present study, this paper will only focus on nominal case marking of ergative languages with a belief that verb conjugational agreement will be a trivial issue if nominal case marking of ergativity is appropriately accounted. The following figure illustrates the alignment of accusative and ergative languages.

WANG Ran, Ph.D. Candidate, Department of Linguistics, University at Buffalo, SUNY, Buffalo, USA.

${ }^{1}$ Core arguments in this paper refer to obligatory arguments of a verb that receive core cases such as nominative, accusative, ergative, and absolutive case. Other cases such as locative, instrumental cases are referred as peripheral case. Ditransitive verbs will not be a topic of this paper. 


\begin{tabular}{|l|l|l|}
\hline \multirow{2}{*}{ Nominative } & A & Ergative \\
\cline { 2 - 2 } & $\mathrm{S}$ & \multirow{2}{*}{ Absolutive } \\
\hline Accusative & $\mathrm{P}$ & \\
\hline
\end{tabular}

There are also many languages that have split ergativity in which some Ss are treated together as A while others are treated as P. Split ergativity places difficulty in any formal treatment towards ergativity because whether an S would be treated as A or P is related to particular verb and it seems we should include such information in the lexical entry of each verb. However, this is also beyond the topic of the present paper.

To summarize, in this paper I would like to talk about ergativity is a very strict sense that (a) the ergativity is nominally marked; (b) the related verbs are either transitive or intransitive, (c) all kinds of split ergativity are not concerned. But I believe if nominal marking of ergativity is properly addressed, related issue on verb agreement and split ergativity will become a lot easier.

\section{Antipassive Construction in Ergative Languages}

I also define the definition of antipassive construction following Dixon (1994, p. 146). Similar to passivization that promotes $\mathrm{P}$ of the transitive clause to $\mathrm{S}$ of the derived intransitive clause in passive voice, antipassivization promotes $\mathrm{A}$ in the transitive clause to $\mathrm{S}$ of the derived intransitive clause in antipassive voice. In both of the derivation, cases are reassigned. In passivization, the underlying P is in accusative case and the argument is marked by nominative case in syntactic surface, whereas in antipassivization, the underlying A is in ergative case and the argument receives absolutive case in the derivation. Unrelated arguments (A in passivization and $\mathrm{P}$ in antipassivization) are reduced to peripheral cases and become optional. Example (1) shows passivization in English while (2) shows antipassivization in Kalkatungu ${ }^{2}$ (Blake, 2001, p. 115, cf. Blake, 1979).

(1) a. I chased him.

b. He is chased by me.

(2) a. Kuntu wampa-ngku kaun muu-yan-puni-mi not girl-ERG ${ }^{3}$ dress.NOM ${ }^{4}$ dirt-PROP-CAUS-FUT

The girl will not dirty the dress.

b. Kuntu wampa kaun-ku muu-yan-puni-yi-mi not girl.NOM dress-DAT dirt-PROP-INCH-AP-FUT

The girl will not dirty [her] dresses.

In both (1a) and (2a) the verbs are transitive verbs taking two arguments. In (1a) the A argument "I" is in nominative case while the P argument is in accusative case. But in (1b), the passive voice version, the P NP in (1a) has been raised to $S$ and received nominative case whereas A NP in (1a) reduced to peripheral propositional phrase marked by by. Similarly, in (2b) the verb is a causivized muu, the P NP wampa marked by ergative case marker becomes S NP in (2b) at the same time receives nominative case marking and P NP in (2a) reduced to dative peripheral argument.

\footnotetext{
${ }^{2}$ Kalkatungu is a distinct Australian language.

${ }^{3}$ In this paper cases are abbreviated as following: ABS (absolutive), DAT (dative), ERG (ergative). Other crucial abbreviations are: AP (antipassive), CAUS (causative).

${ }^{4}$ The data marks in this way. But given the fact that in most languages, nominative case and absolutive case tend to be zero marked, I think in this case, it is only a trivial terminological issue. In any way the case marking does not make a difference in showing antipassivization.
} 


\section{Pivot Construction in Ergative Languages}

Many languages involve pivot construction to link clauses with same referent. Pivot construction is an important feature to explore in the study of ergativity because, according to Dixon (1994, p. 154), a language could be a syntactically ergative language if it has S/P pivot, that is, the co-referential arguments are $\mathrm{S}$ and $\mathrm{P}$ in each clause respectively. What makes things more complicated is that a morphologically ergative language aligning $\mathrm{S}$ and $\mathrm{A}$ in case marking may be not syntactically ergative. I will discuss this in the following sessions.

S/P pivots. S/P pivot refers to the case that the shared pivot is $S$ in one clause and $P$ in the other if one of the clauses is intransitive. The following example (3) in Dyirbal is an example of S/P pivot. There are two sub-clauses in (3), the one that says (a) "mother saw father" and the one that says (b) "father returned". The shared argument of the two sub-clauses is the "father" which is the P NP in (a) and S NP in (b), therefore it is an S/P pivots.

$\begin{array}{llll}\text { (3) yuma } & \text { yabu-ngu } & \text { buran } & \varnothing \quad \text { banagan }^{\mathrm{y}} \mathrm{u} \\ \text { father.ABS } & \text { mother-ERG } & \text { saw } & \text { returned }\end{array}$

Mother saw father and he returned.

S/A pivots. S/A pivot refers to the case that the shared pivot is $\mathrm{S}$ in one clause and $\mathrm{A}$ in the other if one of the clause is intransitive. The following example (4) in English is an example of S/A pivot. In (4), the shared argument is "mother" which is A in "mother saw father" and S in "mother returned".

(4) Mother saw father and returned.

(5) yanpayi-ø pa-ø-ø papatjani-njiřa-tja:

Man-ABS INDIC-3-SG cry.out-ALWAYS-tja

tjunani ma-ø-ø-njanu pamař-tjati-lu

cut INDIC-3-SG-REFL stone-WITH-ERG

The man was always calling out and cutting himself with stones.

Example (5) shows that ergative languages (Walmatjari ${ }^{5}$, cf. Dixon, 1994, p. 174) may also have an S/A pivot. In (5) the two sub-clauses are (a) "the man was always crying out" and (b) "he was always cutting himself with stone". The shared argument is "the man". It is the S in (a) and A in (b). This example, together with (3), shows it is possible that ergative languages use both S/A and S/P pivot construction in linking clauses.

Mixed pivots. It is also possible that a language uses both S/A and S/P pivot constructions. This could be illustrated with the following example (6) in Tongan ${ }^{6}$ (Dixon, 1994, p. 176).

(6) a. na'e tā'i'a a Mele 'e Hina mo kata

PAST hit ABS Mary ERG Hina and laugh

Hina hit Mary and Hina (simultaneously) laughed.

$\begin{array}{llllllll}\text { b. na'e } & \text { tā'i'a } & \text { a } & \text { Mele } & \text { 'e } & \text { Hina } & \text { 'o } & \text { kata } \\ \text { PAST } & \text { hit } & \text { ABS } & \text { Mary } & \text { ERG } & \text { Hina } & \text { as a result laugh }\end{array}$

Hina hit Mary and as a result Mary laughed.

It is quite obvious that (6a) involves S/A pivot and (6b) employs S/P pivot. The only difference between the two sentences is the coordination word mo and 'o. It is unclear why such words may decide the pivot type of the whole sentence. But these examples show there are ergative languages that use both types of pivot construction in utterance.

\footnotetext{
5 Walmatjari is a Pama-Nyungan language spoken in Australia. It is reported to have a split ergative case system (Hudson, 1976, pp. 9-12).

${ }_{6}$ Tongan is an Austronesian language spoken in Tonga.
} 


\section{HPSG Treatment and Problems}

Various proposals have been made to account for ergativity. Syntactic accusativity account (Anderson, 1976) assumes $\mathrm{S}$ and $\mathrm{A}$ are in subject position and $\mathrm{P}$ is in object position, which makes morphologically ergative languages syntactically accusative. There is also an approach that treats the absolutive-S as the object of the clause (Bobaljik, 1992). But this approach is quite unnatural if the notion of "object" is not redefined.

\section{Inverse Grammatical Relations}

Manning proposed the Inverse Grammatical Relations account in his dissertation. It says that syntactically ergative languages are always using an inverse mapping for transitive verb (Manning, 1995, p. 42). In this approach, accusativity involves mapping a-structure (agent) to subject in gr-structure (grammatical structure) and patient to object, meanwhile, syntactic ergativity involves mapping a-structure to object and patient subject. The ergative system is exactly the inverse version of the accusative system. In his analysis, since the inverse in grammatical relations, the antipassivization in ergative languages is exactly the same with the passivization in accusative language.

Manning's proposal seems to be a good fit to HPSG; because intuitively, we could just rewrite the word entry and passivization rule to generate antipassivization rule for ergative languages. The word entries and antipassivization rule may be illustrated as (7).

(7) a. transitive verb word entry

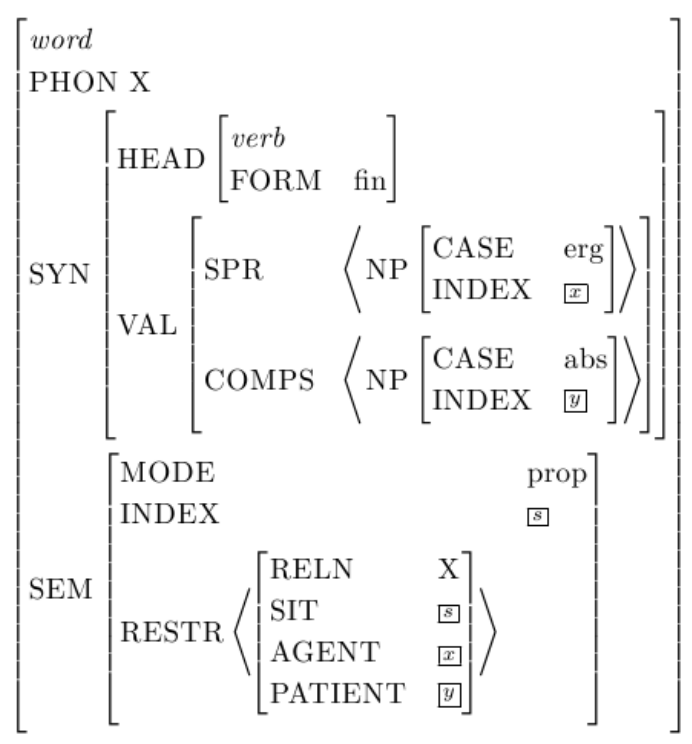


b. intransitive verb word entry

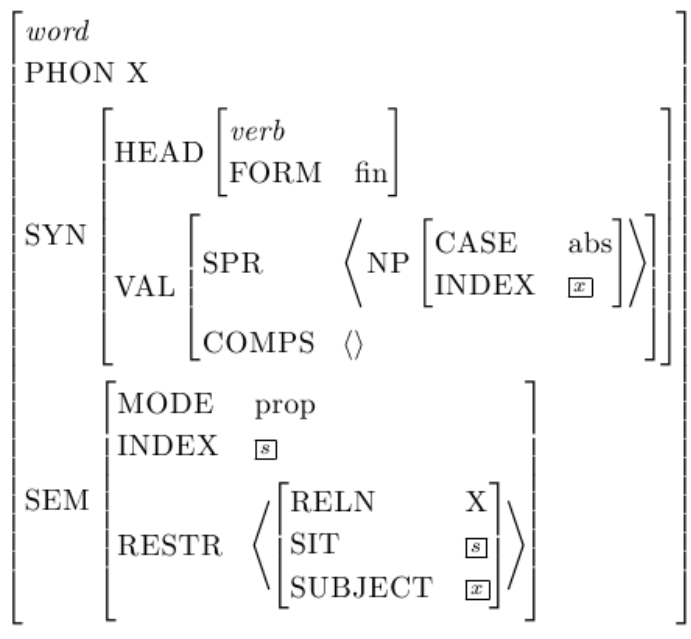

c. antipassivization rule

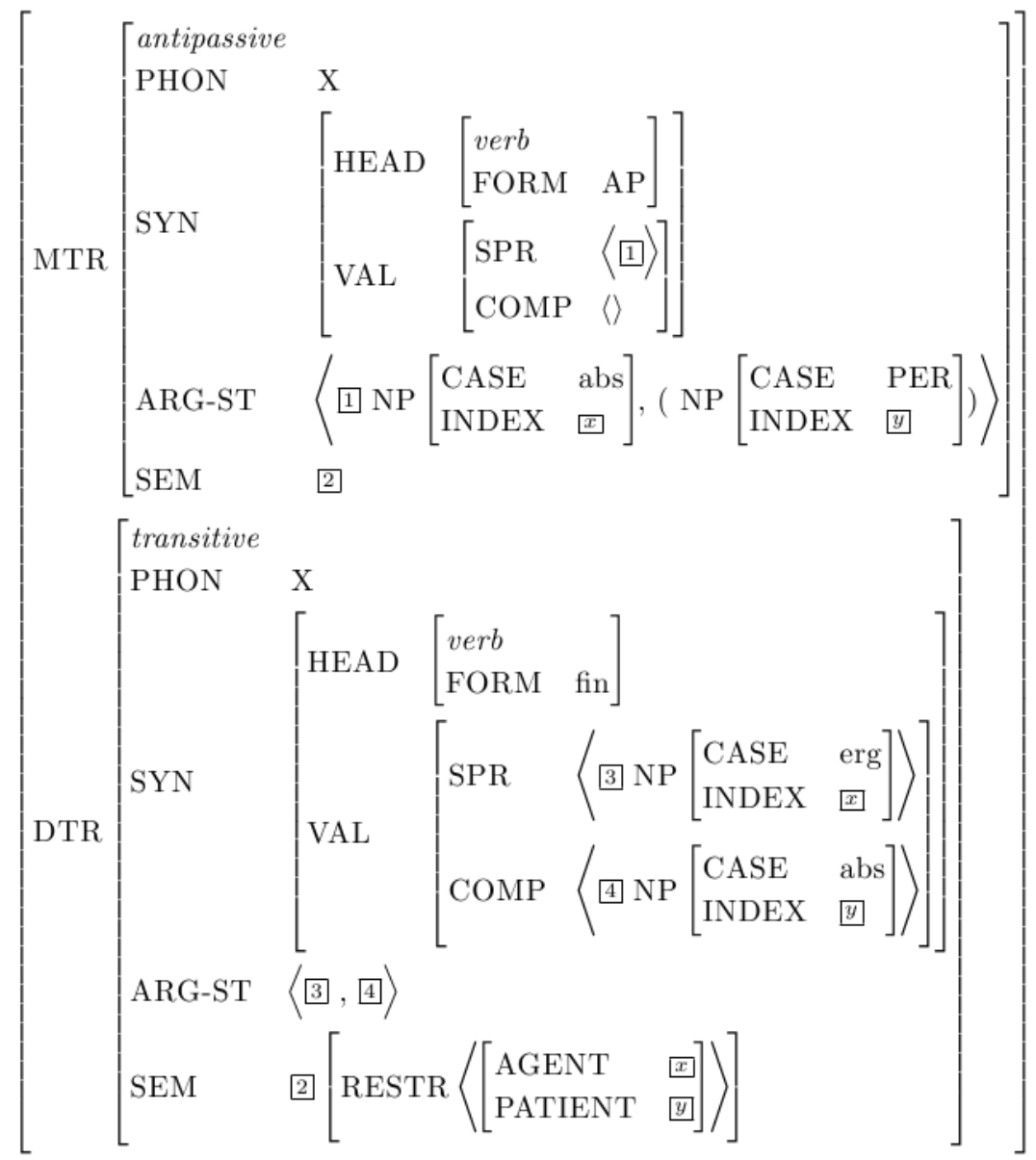

As shown in (7a) the transitive verb has a specifier NP and a complement NP which are marked in ergative and absolutive case respectively. The specifier NP co-refers to agent in semantics of the verb and the complement NP co-refers patient. In (7b), the intransitive verb has one specifier NP. It is marked in absolutive case and it co-refers subject in semantics. And in (7c), the rule for antipassive construction, in the mother node, the verb form was labeled as antipassive. The specifier list has an NP in absolutive case co-referring the agent 
and there is another optional NP in peripheral case co-indexing the patient in the daughter semantics. Notice that the valence of the output is reduced by one shown by the empty complementizer list in the mother node.

\section{Data under HPSG}

All antipassivization of syntactically ergative languages can be covered by the rule shown in (7c). Taking sentences in (2) for example, the verb in this antipassivization process is the muu-yan-puni-mi "dirt". It takes two NPs, the specifier "girl" in ergative case and the complementizer "dress" in absolutive, which correspond $\mathrm{NP}_{3}$ and $\mathrm{NP}_{4}$ respectively in the figure for (7c). After the antipassivization, $\mathrm{NP}_{3}$ is assigned the absolutive case (the data marks as nominative) and $\mathrm{NP}_{4}$ gets peripheral case, in this language and in this case, the dative case.

This HPSG account for antipassivization is simple and it could correctly generate sentences in antipassive voice in syntactically ergative languages. However, this approach is quite limited to this kind of ergativity. And sadly, only one language, namely Dyirbal, is commonly accepted as syntactically ergative according to Butt (2006, p. 163) and Manning (1995). The majority of ergative languages have certain kinds of irregularity, either they use different pivot construction or they have a split ergative system or both. I would like to discuss the limitation in more detail in the following session.

\section{Problems With the Simple HPSG Account}

One of the problems of the aforementioned HPSG account is that it specifies the cases of the output of antipassivization. That makes the rule quite fixed resulting in the incapability of catching facts on split ergativity and ergative pivot construction. In fact, if we re-exam $(7 a, 7 b)$ we find that the ergative case of the specifier NP in (7a) is actually assigned to the NP because it is the A of the transitive verb. This is automatically true given our definition of ergativity. It would be redundant to specify the case in this stage and it is also unwise, because the case value becomes fixed in lexical level, making it impossible to interact with other sub-clauses on a higher level. And importantly, this interaction is important in explaining different pivot constructions previously mentioned in section "Pivot Construction in Ergative Languages".

I want to re-introduce (5) here as (8) to explain in a more detailed way.
(8) yanpayi-ø
pa- $\varnothing-\varnothing$
papatjani-njiřa-tja:
Man-ABS
INDIC-3-SG
cry.out-ALWAYS-tja
tjunani ma-ø-ø-njanu
pamař-tjati-lu
cut
INDIC-3-SG-REFL stone-WITH-ERG

The man was always calling out and cutting himself with stones.

Once again, there are two sub-clauses in (8): (a) The man was always crying out; and (b) the man was always cutting himself with stones. In (a) the shared argument, the man, is the $\mathrm{S}$ in an intransitive clause, and in (b) it is the A of a transitive clause. If the case of each of the NP is fixed at the lexical level, the man should bear absolutive case in (a) and ergative case in (b). It then will be really unnatural to proceed further on the combination of the two sub-clauses because the shared argument has different case value in each sub-clause. If that is true, sentence (8) will be impossible. To account for the S/A pivot constructions like that in (8), we want the case value to be fixed and spelt out at a later level. And it is based on this observation that we want to refine the previous simple HPSG account.

\section{Proposal of a Modified HPSG}

In general we want case to be assigned to the NP after the coordination of the sub-clauses so that more 
consideration could be taken and the case-assignment is more flexible to include more data.

I would like to advance a proposal that treat the pivot constructions similar to unbounded dependency constructions, in which we have a GAP feature telling us that an argument is needed until it is checked by the designated filler. This is not a wilder imagination because we do find something similar between pivot constructions and unbounded dependency constructions. First of all, in both structures, one argument is missing from its default place in the clause. Secondly, a "filler" is overt somewhere in the intra-clausal context. Thirdly, the missing argument and the "filler" co-refer a same semantics. These similarities should be noticed and might be helpful in explaining pivot constructions in (8). Therefore, I propose further a new feature called pivot under the semantics of verb. It takes value from agent, patient, or subject from the RESTR list and keeps it to upper nodes until the designated NP is found and checked it. It works in a similar fashion with GAP feature in unbounded dependencies. Moreover, the case value should be kept unspecified in lexical level. The case value is only assigned when the clause structure is done and the value should be that of its "filler".

Taking (8) again for example, for the (a) "the man was always crying out", the lexical entry for the verb is illustrated in (9a), for (b) "the man was always cutting himself with a stone", the lexical entry of the verb is shown in (9b).

(9) a. lexical entry for papatjani (intransitive)

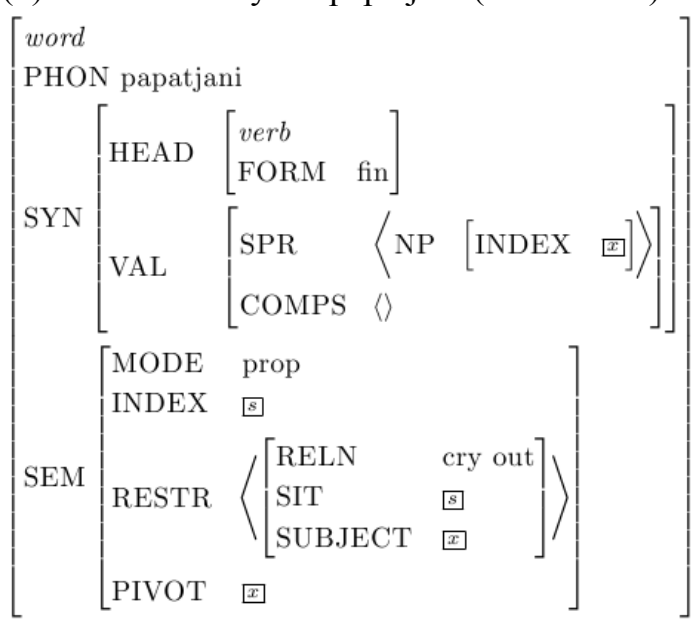

b. lexical entry for tjunani (transitive)

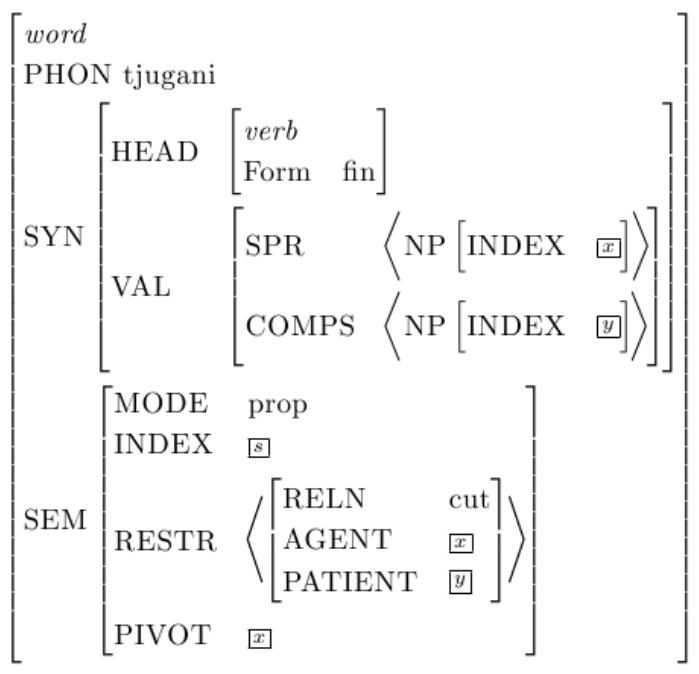


In (9a) and (9b) the case values of the NPs are removed, but due to the semantic index, we are still able to know which role a particular NP is playing in the clause. The value of pivot is word specific. This could help us deal with cases in split ergativity and pivot construction. I would show in a more detailed way in next section.

\section{Modified Antipassivization Rule}

In the same light as we discussed before, the antipassivization rule should be modified and the new rule is illustrated in (10)

(10) antipassivization rule (revised)

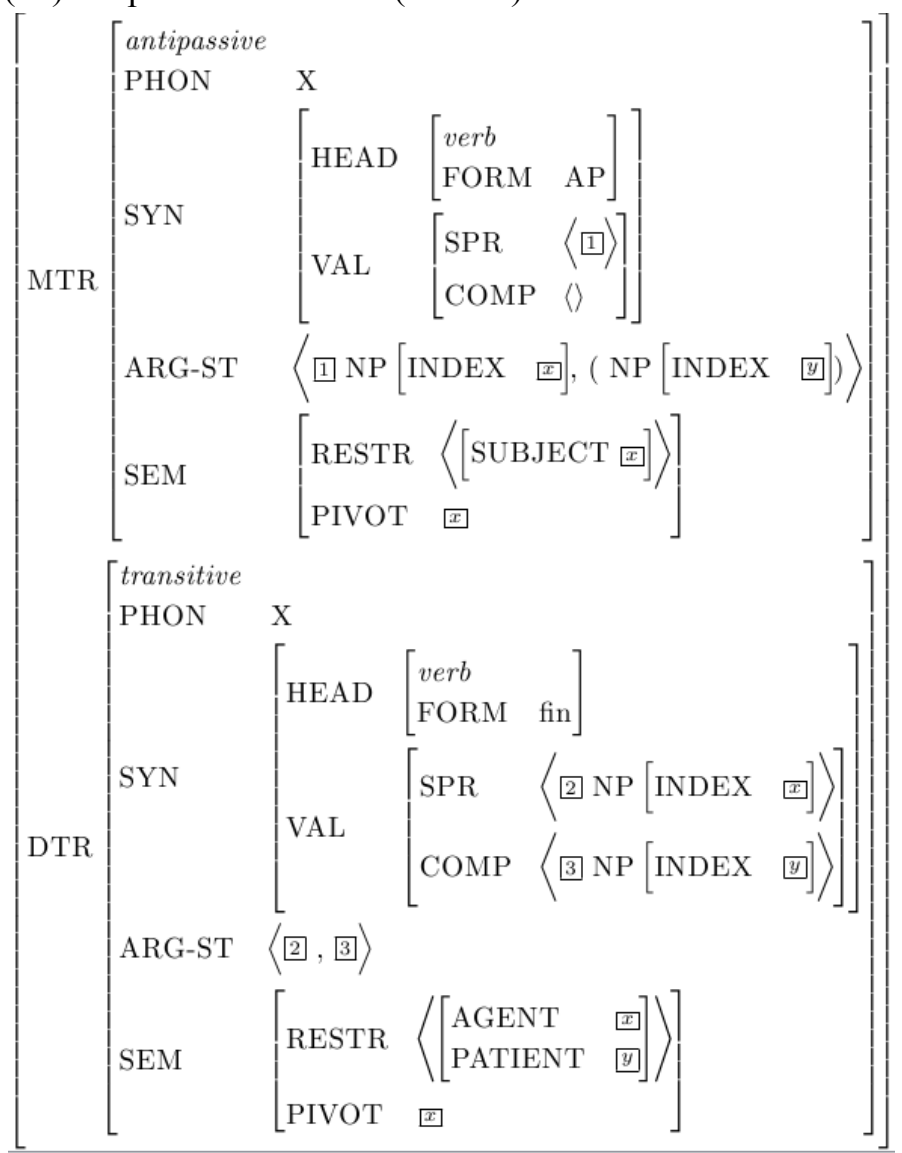

In the antipassive rule, the transitive input has a pivot in its semantics, and the pivot is carried up to the mother node. All case features are unspecified here in the rule. This enables us to leave the case issue to the end and thusly take account for the pivot construction.

\section{Pivot Construction Rule}

Pivot construction rule addresses the case assignment issue for pivot constructions. Basically pivot value of the daughter nodes is carried up to an upper node if it does not meet the NP designated by indexing to resolve it.

Take (8) for example, the tree for the pivot construction is shown in (11).

(11) pivot construction for (8). 


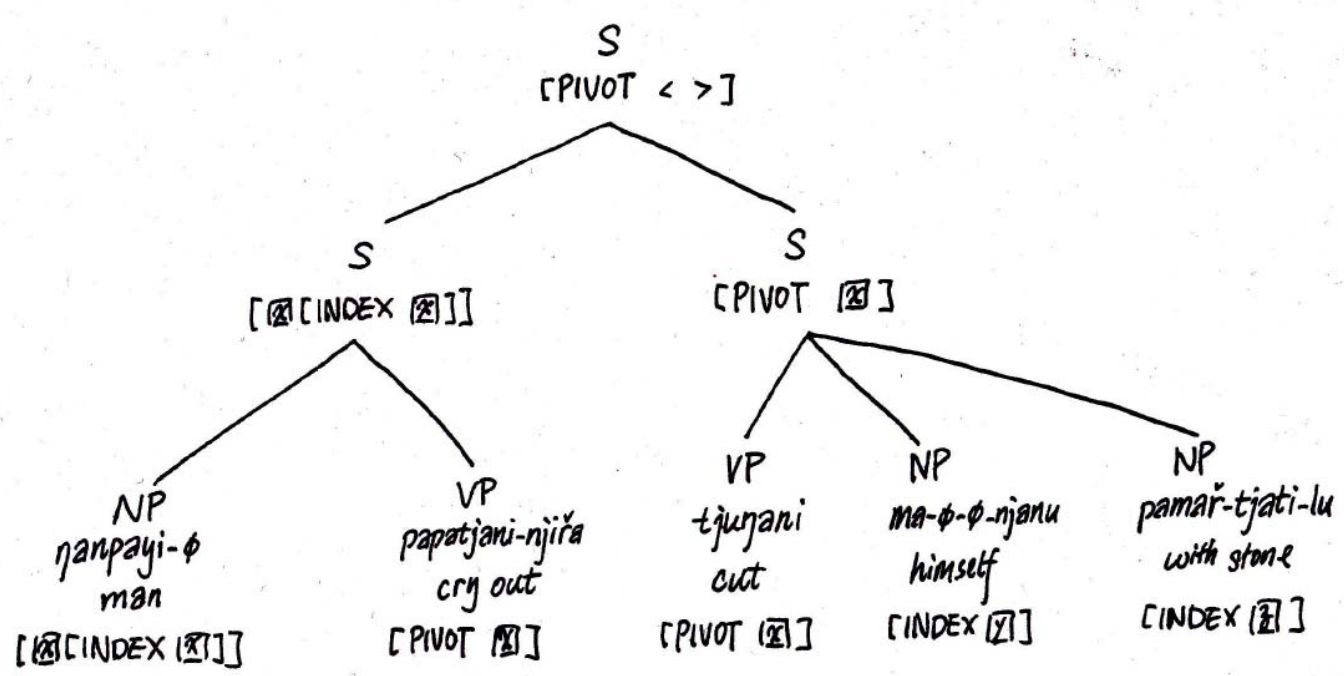

In this illustration, all irrelevant features have been removed. The verb "cut" has a pivot co-referring $\mathrm{x}$-argument, but it fails to find $\mathrm{x}$-index in its local environment, so the pivot value is carried up to the upper S node, therefore it has the pivot value. At the other side of the coordination, the pivot of the verb "cry out" finds its $\mathrm{X}$-argument and is therefore resolved, leaving the upper $\mathrm{S}$ node no pivot value. Because the left $\mathrm{S}$ has the $\mathrm{x}$-argument for the pivot in the right $\mathrm{S}$, that value is resolved again leaving the uppermost $\mathrm{S}$ no pivot value. The case of the shared argument is the same as it should be in the left $\mathrm{S}$, namely, absolutive case, because it is the subject of the intransitive clause which takes absolutive case by definition. Although in the right side, the shared NP should have ergative case, but since it does not actually have that argument, there is no actual NP for the ergative case, therefore the ergative case does not show up. The whole sentence ends up with S/A pivot with the shared argument marked with absolutive case.

\section{Conclusion}

This paper briefly discussed the antipassivization and pivot construction of ergative languages in HPSG approach, particularly emphasizing the case-assignment and structure rules that help derive various pivot constructions.

The advantage of the proposal is threefold. Firstly, the proposed method avoids the case conflict in the P/A pivot construction and correctly derives coordinative pivot construction from two sub-clauses. This is what the simple version HPSG method and the inverse grammatical relation approach cannot do. Secondly, Dixon (1994), Butt (2006), Blake (2001), Manning (2005), and lots of other linguists have emphasized that there is a semantic reason for ergativity. This proposed method keep the syntactic case feature unspecified and let the semantic pivot and index work together to decide the case of the surface argument, which is a more faithful method to the semantic basis of ergativity. Third, the present paper leaves enough room for further study in ergative case assignment and many other phenomena in related fields.

Further study may involve using the proposed method to discuss more data and extend this method to explain mixed pivot construction, to further investigate split ergativity and to discuss the semantic basis of case assignment. 


\section{References}

Anderson, S. R. (1976). On the notion of subject in ergative languages. In Subject and topic (pp. 1-23). New York: Academic Press.

Blake, B. J. (2001). Case. Cambridge: Cambridge University Press.

Bobaljik, J. D. (1992). Nominally absolutive is not absolutely nominative. In The Proceedings of the Eleventh West Coast Conference on Formal Linguistics (pp. 44-60). Stanford, C. A.: Stanford Linguistic Association.

Butt, M. (2006). Theories of case. Cambridge: Cambridge University Press.

Dixon, R. M. W. (1994). Ergativity. Cambridge: Cambridge University Press.

Hudson, J. (1976). Walmatjari: Nominative-ergative or nominative-accusative. In Papers in Australian linguistics (pp. 1-30). Canberra: Pacific Linguistics.

Manning, C. D. (1995). Ergativity: Argument structure and grammatical relations (Dissertation). 